\title{
Cerebral ganglioglio-neuroblastoma: an unusual brain tumour of the neuron series
}

\author{
DARAB K DASTUR \\ From the Neuropathology Unit, Post-Graduate Research Laboratories, Grant Medical College and \\ JJ Group of Hospitals, Bombay, India
}

SUMMARY The pathology of an unusual intracranial neuroectodermal tumour of the neuron series is described and its possible histogenesis discussed. The tumour, in a child aged 5 years with an enlarged head since infancy, presented as a large solid intra-cerebral mass. Histological examination showed four types of cells; (i) the stroma, forming the bulk of the tumour, was astrocytomatous; (ii) lobules of ill defined cells bearing small circular nuclei, representing immature neuroblasts; (iii) the same or other lobules containing neurons in various stages of development; and (iv) dense clusters of cells with hyperchromatic nuclei attempting rosettes, representing an overtly malignant neuroblastoma. This tumour was designated "ganglioglio-neuroblastoma" and probably originated from a slow growing ganglioglioma.

A brief account of cerebral neuroblastoma was given 20 years ago by Russell and Rubinstein ${ }^{1}$ in the first edition of their book. However, Horten and Rubinstein $^{2}$ through their detailed pathological report of 35 cases may be said to have established the cerebral neuroblastoma as a nosological entity with a characteristic lobulated structure and a tendency to form Homer Wright rosettes, to be desmoplastic, and to disseminate within and outside the CNS. The publications of Feigin and Budzilovich ${ }^{3}$ and Ahdeveara et $a l^{4}$ also discussed the histologic appearance and the histogenesis of the cerebral neuroblastoma, which clearly emerges as the most readily identifiable tumour of the neuron and its precursor cells in the supratentorial compartment. Fine structural examination of a few specimens has revealed dense core vesicles, but no synaptic structures. ${ }^{5}$ It is generally recognised that, in contrast to the glial cell tumours where dedifferentiation is frequent and leads to more anaplastic forms, tumours of the neuron series arise from primitive cells and may show differentiation to maturer cell

Address for reprint requests: Director-Department of Neuropathology and Applied Biology, MRC 15th Floor, Bombay Hospital, Bombay 400 020, India.

Received 1 July 1981 and in revised form 28 September 1981 Accepted 19 October 1981 types. ${ }^{36}$ The subject has been very adequately summarised recently by Russell and Rubinstein ${ }^{7}$ and Rubinstein and Herman. ${ }^{8}$ In a chapter devoted to neuroblastoma and ganglioneuroma, Willis ${ }^{9}$ does not report any neuroblastoma of the central nervous system.

\section{Material and methods}

In a recent review of brain tumours of the neuron series, from this Unit, ${ }^{10}$ we have separated out five specimens as probable cerebral neuroblastomas; these were previously diagnosed as an unclear anaplastic neuroectodermal tumour, or a bizarre glioma, or a supratentorial tumour resembling a cerebellar medulloblastoma. In addition we have one medullo-epithelioma, a typical olfactory neuroblastoma and two ganglio-gliomas; all were briefly described in the pathological analysis of the first 1000 intra-cranial space-occupying lesions examined at our Unit. ${ }^{11}$ During the same period of about 25 years that yielded the above listed nine interesting supratentorial tumours of the neuron series, we have had just under 100 medulloblastomas from the posterior fossa.

The present report deals with a histo-pathological evaluation and histogenetic consideration of one of the two gangliogliomas which has shown prominent neuroblastomatous components. Only histopathologic examination by light microscopy has been employed. Paraffin sections stained with haematoxylin and eosin, phosphotungstic-acid-haematoxylin, Gomori's reticulin, 
Cresylechtviolet and Holmes' silver impregnation methods, have been examined. As only paraffin embedded material was available, frozen sections could not be obtained and electron microscopy was not done.

Clinical features (Reg. No. 3402/1960) JK, boy aged 5 years, was admitted to the neurosurgical ward of $\mathbf{J J}$ Hospitals, with a history of inability to walk, sit up, or even support the head, probably since infancy. There was a further history of a fit followed by unconsciousness 5 months earlier. Fits recurred at 8-10 days intervals, till

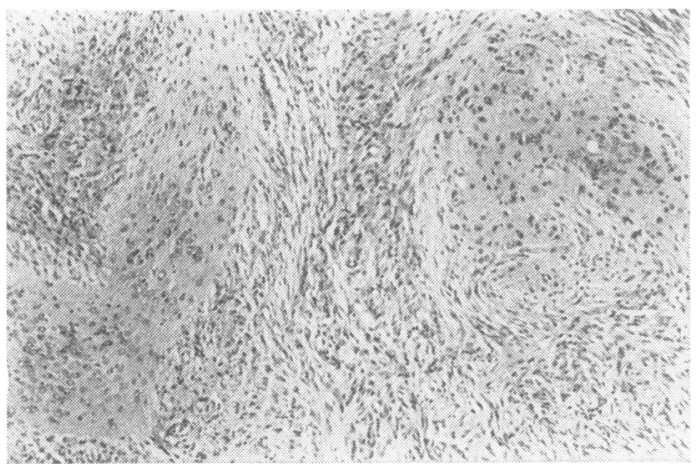

Fig 1 (NP-B-188): Lobulated part of cerebral tumour: two lobules of cells of the neuron series in a matrix of gliomatous tumour. (Haematoxylin and Eosin $\times 65$.) gradually he was bedridden and having involuntary movements of all the four limbs on the slightest provocation. He was said to have had a large head since birth. A skull radiograph showed separation of the right frontoparieto-temporal suture by more than $2.5 \mathrm{~cm}$. Through the gap, soft non-pulsatile intra-cranial contents could be felt. Raised intracranial tension was indicated by a "beaten silver" appearance on the radiograph, but there was no erosion or calcification within the skull. There was frontal bossing and a "cracked-pot" sound. On carotid angiography there was marked shift of the middle cerebral artery upward and laterally.

Operative findings Fronto-parietal craniotomy (neurosurgeon Dr G Sinh) revealed a large tumour, extending from one frontal pole backward through the parietal lobe and across the midline into the opposite hemisphere. The tumour was mainly firm, nodular and not very vascular but was cystic in places. Only parts of the tumour could be removed. The patient died 48 hours later with peripheral vascular failure. There was no necropsy.

Histopathological findings (NP-B-188) The tumour pieces received in formalin were greyish with a few darker spots, and uniformly firm. Paraffin sections revealed four types of cells arranged in different ways. (1) There was a matrix of elongated cells with ovoid or fusiform nuclei, and occasionally bearing calcospherites, in which there were islands or areas of other kinds of tumour cells (fig 1). The matrix cells appeared to be either astrocytes or
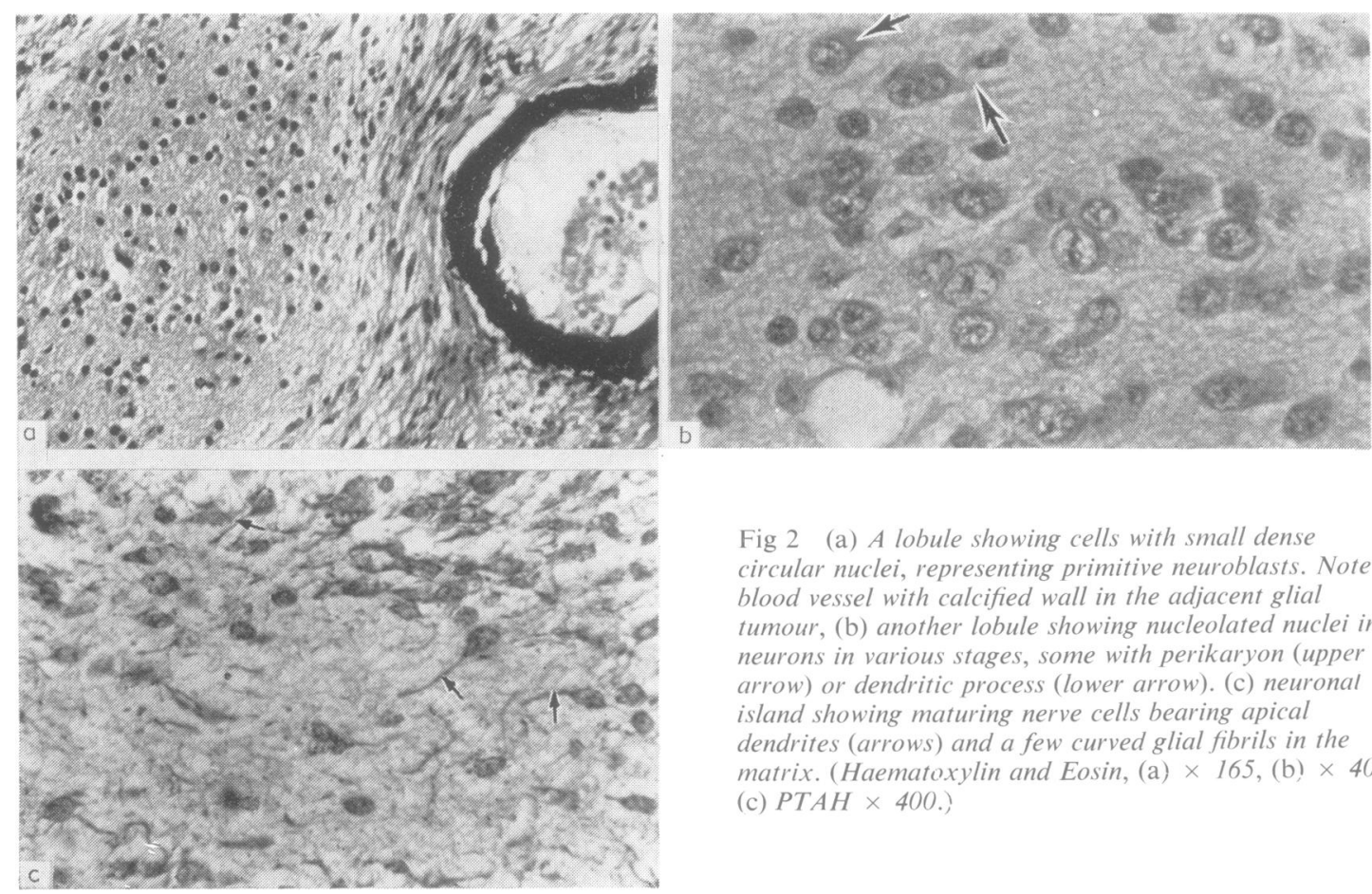

Fig 2 (a) A lobule showing cells with small dense circular nuclei, representing primitive neuroblasts. Note a blood vessel with calcified wall in the adjacent glial tumour, (b) another lobule showing nucleolated nuclei in neurons in various stages, some with perikaryon (upper arrow) or dendritic process (lower arrow). (c) neuronal island showing maturing nerve cells bearing apical dendrites (arrows) and a few curved glial fibrils in the matrix. (Haematoxylin and Eosin, (a) $\times 165$, (b) $\times 400$, (c) $P T A H \times 400$.) 


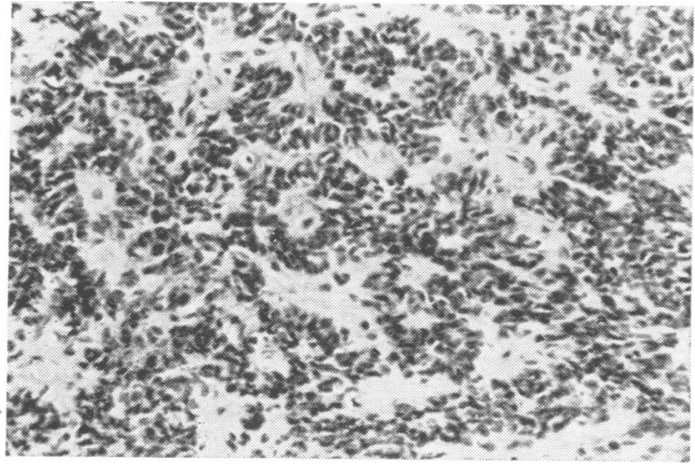

Fig 3 Neuroblastomatous part of the tumour, showing tumour cells around central cores or central spaces. (Haematoxylin and Eosin $\times$ 165.)

fibroblasts; PTAH stain confirmed that they were almost exclusively astrocytes with a rich content of glial fibrils. Reticulin stain showed only vascular reticulin in both the matrix and the other parts of tumour tissue. Some of the blood vessels showed a calcified wall (fig 2a). (2) Some of the islands of tumour tissue consisted of ill-defined cells with small dense circular nuclei (fig $2 a$ ), suggestive of primitive cells such as neuroblasts. (3) Many of these islands included clearly recognisable neurons in various stages of maturation (fig 2b). Closer examination revealed large vesicular nucleolated nuclei, often with amphophilic cytoplasm (upper arrow, fig 2b), indicative of mature neurons. Occasionally, a cytoplasmic process was seen emerging from these cells (lower arrow, fig $2 \mathrm{~b}$ ). These processes appeared to be apical dendrites and were more clearly identified in PTAH preparations (fig 2c), than in silver-impregnated paraffin sections. Thus the tumour as described so far showed the features of a ganglioglioma with primitive neuroblasts as well.

(4) The fourth type of cell stood out clearly because of its denser aggregation in clusters, cords or rosettes, in the gliomatous matrix. These cells were larger with prominent ovoid hyperchromatic nuclei. There was a tendency for them to be disposed around a central cytoplasmic core, or a small central canal or space, constituting Wright rosettes and Flexner rosettes (fig 3). This fourth type of tumour tissue was interpreted to be an actively growing neuroblastoma.

\section{Discussion}

The cerebral ganglioglioma is a rare tumour consisting of neoplastic glial cells, and ganglion cells which may or may not be neoplastic. The wide spectrum of cellular activity of the gangliogliomas extends from almost hamartomatous to malignant forms, as discussed by Russell and Rubinstein. ${ }^{7}$ Usually the glial components undergo malignant evolution, ${ }^{12}$ but the neuronal elements may also become anaplastic. ${ }^{3}$ A few of these tumours contain foci of neuroblasts and are interpreted as transitional forms between gangliocytomas and cerebral neuroblastomas. Such "transitional" tumours, occurring either in the central or peripheral nervous system, have been designated "ganglioneuroblastomas" or "malignant ganglioneuromas"?

The tumour described here, probably arising in infancy and presenting as a large cerebral mass at the age of 5 years, showed at least four distinct cell types, including two types of neuroblastoma cells and obviously mature neurons. The more overtly neoplastic cells were the glial cells, predominantly astrocytic, and the chords and rosettes of neuroblasts with large hyperchromatic nuclei, constituting a malignant neuroblastoma. In fact the latter tumour may have been rapidly growing and responsible for the severe terminal symptoms of increased intracranial tension in a child with enlarged head since infancy.

This tumour also provided interesting histological evidence of the possible origin of somewhat mature neurons with a large vesicular nucleus and a short apical dendritic process, from cells with no discernible perikaryon and a dense circular nucleus, as the two often co-existed in the same area in varying proportions. The latter (as in fig $2 \mathrm{a}$ ) were reminiscent of the cerebellar granular neurons and may, rarely, be encountered as a part of a cerebellar medulloblastoma and create the impression of a cerebellar "medullo-neuroblastoma" (Dastur, unpublished observations). Rubinstein (1979, personal communication) also accepts the possibility of a cerebellar neuroblastoma; such as that described by Shin et al. ${ }^{13}$ With its complex combination of cell types and growth behaviour, this tumour is best described as a "ganglioglio-neuroblastoma".

Grateful acknowledgement is due to Dr Gajendra Sinh, Neurosurgeon, for referring the material of the case, to Dr LJ Rubinstein, Professor of Neuropathology, Stanford, USA, for his valuable comments, and to Sir HN Mody and Lady Manekbai Mody Trust for research support.

\section{References}

${ }^{1}$ Russell DS, Rubinstein LJ. Pathology of tumours of the nervous system. 1st ed. Baltimore: Williams and Wilkins, 1959.

${ }^{2}$ Horten BC, Rubinstein LJ. Primary cerebral neuroblastomas. A clinicopathological study of 35 cases. Brain 1976;99:735-56.

${ }^{3}$ Feigin I, Budzilovich GN. Tumours of neurons and their precursors. J Neuropath Exp Neurol 1974;33: 483-506.

${ }^{4}$ Ahdevaara P, Kalimo H, Torma T, Haltia M. Differentiating intracerebral neuroblastoma. Report of a case and a review of the literature. Cancer 1977;40: 
784-8.

5 Azzarelli B, Richards DE, Anton AH, Roessmann U. Central neuroblastoma; electron microscopic observations and catecholamine determinations. $J$ Neuropath Exp Neurol 1977;36:384-97.

${ }^{6}$ Rubinstein LJ. Cytogenesis and differentiation of primitive central neuroepithelial tumours. J Neuropath Exp Neurol 1972;31 :7-26.

${ }^{7}$ Russell DS, Rubinstein LJ. Pathology of tumours of nervous system. 4th ed. Baltimore: Williams and Wilkins, 1977;244-70.

${ }^{8}$ Rubinstein LJ, Herman MM. Recent advances in human neurooncology. In: Smith WT, Cavanagh JB, eds. Recent advances in neuropathology. Edinburgh: Churchill Livingstone, 1979;179-224.

${ }^{9}$ Willis RA. The pathology of the tumours of children. Edinburgh: Oliver and Boyd, 1962;7-35.
${ }^{10}$ Dastur DK, Lalitha VS. Neuroectodermal tumours of the central nervious system II: Tumours of the neurons series. In: Proceedings of National Seminar on Neuro-Oncology. NIMHANS, Bangalore, 1979 (In Press).

${ }^{11}$ Dastur DK, Lalitha VS. Pathological analysis of intracranial space-occupying lesions in 1000 cases, including children. Part II: Incidence, types and unususal cases of glioma. $J$ Neurol Sci 1969;8:143-70.

${ }^{12}$ Christensen E. Nerve cell tumours (central and peripheral). In: Minckler J, ed. Pathology of the Nervous system, vol 2, New York: McGraw-Hill, 1971, 208193.

${ }^{13}$ Shin NY, Laufer H, Lee YC, Aftalion B, Hirano A, Zimmerman HM. Fine structure of a cerebellar neuroblastoma. Acta Neuropath 1978;42:11-13. 